\title{
О БИОЛОГИЧЕСКОЙ АКТИВНОСТИ СТАБИЛИЗИРОВАННЫХ АРАБИНОГАЛАКТАНОМ НАНОЧАСТИЦ СЕРЕБРА В ОТНОШЕНИИ КРЕСС-САЛАТА Lepidium sativum L. Curled И ФИТОПАТОГЕННОГО МИКРОМИЦЕТА Fusarium sambucinum ${ }^{*}$
}

\author{
О.И. ГУДКОВА' 1 Н.В. БОБКОВА' 1 , Н.Б. ФЕЛЬДМАН 1 $₫$, А.Н. ЛУФЕРОВ 1 ,

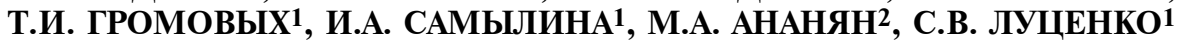

Применение в растениеводстве нанотехнологий, позволяющих получать наночастицы (НЧ) с ростостимулирующим эффектом, антигрибной, антибактериальной и инсектицидной активностью, пролонгированным высвобождением минеральных веществ и гербицидов, открывает перспективы повышения урожайности сельскохозяйственных культур. Среди НЧ металлов, которые могут найти применение в сельском хозяйстве, наночастицы серебра (НЧ Ag) занимают особое место благодаря широкому спектру биологической активности. В настоящей работе нами впервые установлено, что предпосевная обработка семян кресс-салата (Lepidium sativum L.) copтa Curled наночастицами серебра, стабилизированными биополимером арабиногалактаном и диоктилсульфосукцинатом, влияют на энергию прорастания, всхожесть и некоторые анатомо-морфометрические показатели проростков. Также впервые показано, что НЧ Аg оказывают угнетающее действие на рост фитопатогенного гриба Fusarium sambucinum. Целью работы была оценка потенциала использования наночастиц серебра, стабилизированных арабиногалактаном и диоктилсульфосукцинатом, в качестве средства стимуляции роста кресс-салата сорта Curled, а также изучение антифунгального действия полученных наночастиц на фитопатогенный токсинообразующий микромицет Fusarium sambucinum ВКПМ F-900. Синтез наночастиц проводили методом восстановления из нитрата серебра в щелочной среде в присутствии арабиногалактана с последующим добавлением

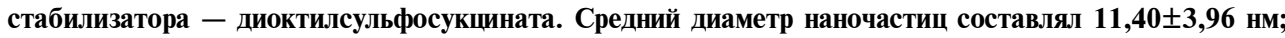
дзета-потенциал -24 мВ. Исследовали влияние НЧ Аg на энергию прорастания, всхожесть семян, рост гипокотиля и корня проростков кресс-салата. Семена инкубировали в течение 1 ч в золях наночастиц с концентрациями серебра 1,$17 ; 2,34 ; 4,69 ; 9,38,18,75 ; 37,5 ; 75$ и 150 мкг/мл. Контрольные группы семян инкубировали в воде. Затем семена проращивали в чашках Петри на влажной фильтровальной бумаге в темноте при $20{ }^{\circ} \mathrm{C}$. На 3-и сут определяли энергию прорастания семян, на 5-е сут - всхожесть, на 7-е сут - длину гипокотиля и главного корня проростков, а также проводили микроскопический анализ срезов корня проростков, обработанных золями со стимулирующей и ингибирующей конщентрациями Аg (соответственно 4,69 и 18,75 мкг/мл). Антифунгальную активность золей Ag с концентрациями от 9,38 до 300 мкг/мл оценивали методом диффузии в агар. В качестве тест-культуры использовали микромицет Fusarium sambucinum Fuckel ВКПМ F-900. Контроль - стерильная вода. Продемонстрировано, что инкубация семян в золях с концентрацией Ag 2,34 и 4,69 мкг/мл оказывала стимулирующее действие на энергию прорастания и всхожесть семян Lepidium sativum. Доза Ag НЧ 4,69 мкг/мл повышала энергию прорастания на $13,5 \%$, всхожесть - на 11,7 \% по сравнению с контролем. Кроме того, концентрации Аg от 1,17 до 4,69 мкг/мл проявляли значительное стимулирующее действие на рост корня (соответственно от 34,4 до 79,1 \%) при некотором замедлении роста гипокотиля. Инкубация семян в золях с концентрацией серебра от 18,75 мкг/мл и выше приводила к значительному снижению энергии прорастания и всхожести, а также подавлению роста растений. Микроскопическое изучение срезов всасывающей зоны корня проростков показало, что НЧ Аg существенно влияют на формирование проводящей системы центрального осевого цилиндра. Число сосудов ксилемы в проростках, обработанных золем серебра в стимулирующей конщентрации 4,69 мкг/мл, было значительно больше в сравнении с контролем, что обусловило более интенсивный рост корневой системы и растения в целом. Также НЧ Аg оказывали угнетающее действие на рост $F$. sambucinum. Диаметр зоны угнетения роста при максимальной концентрации золя 300 мкг/мл составлял $32,4 \pm 4,2$ мм, при концентрации 150 мкг/мл $-28,4 \pm 3,9$ мм. Минимальная концентрация, которая угнетала видимый рост тест-штамма $F$. sambucinum, составляла 18,75 мкг/мл (зона угнетения роста 11,7 $\pm 0,8$ мм). Представленные данные свидетельствуют о возможности применения золей, включающих стабилизированные наночастицы серебра, для стимуляции всхожести и роста растений, а также их защиты от фитопатогенов.

Ключевые слова: наночастицы серебра, рост растений, энергия прорастания, всхожесть семян, антифунгальная активность, Lepidium sativum, Fusarium sambucinum.

* Работа выполнена при поддержке проекта повышения конкурентоспособности ведущих российских университетов среди ведущих мировых научно-образовательных центров (Проект «5-100»). 
Применение биотехнологий и нанотехнологий в сельском хозяйстве перспективно в связи с широкими возможностями увеличить урожайность сельскохозяйственных культур за счет повышения устойчивости растений к заболеваниям, вредителям и неблагоприятным факторам окружающей среды (1). Использование наночастиц (НЧ) с ростостимулирующим эффектом, антигрибной, антибактериальной и инсектицидной активностью, пролонгированным высвобождением минеральных веществ и гербицидов открывает перспективы повышения урожайности сельскохозяйственных культур, увеличения сохранности посевного материала и пищевых продуктов, преодоления дефицита продовольствия (2). Среди наночастиц металлов, которые могут найти применение в сельском хозяйстве, НЧ серебра (НЧ Ag) занимают особое место благодаря широкому спектру биологической активности $(3,4)$.

В настоящее время возрастает интерес к исследованию потенциала НЧ Ag в качестве средства стимуляции роста и защиты растений (5-7). Продемонстрировано, что НЧ $\mathrm{Ag}$, особенно при высоких концентрациях, способны проникать в ткани растений и накапливаться в них $(6,8,9)$. При этом НЧ могут оказывать как стимулирующее, так и ингибирующее действие на рост растений (10), однако для всесторонней оценки возможностей их практического использования, а также изучения механизмов действия на растительный организм требуются дополнительные исследования. Важная область применения НЧ Ag - защита культурных растений от фитопатогенных грибов, которые существенно снижают продуктивность и контаминируют опасными микотоксинами (11) корма для животных и сельскохозяйственную продукцию. Описаны фунгицидные свойства НЧ Ag в отношении фитопатогенных грибов Rhizoctonia solani, Fusarium semitectum (12-14), Bipolaris sorokiniana, Magnaporthe grisea $(15,16)$, Alternaria solani, Pythium spinosum, Pythium aphanidermatum, Cylindrocarpon destructans, Cladosporium cucumerinum, Glomerella cingulata, Didymella bryoniae, Stemphylium lycopersici и Monosporascus cannonballus (17), однако потенциал антифунгальной активности НЧ Ag раскрыт не полностью.

Для всестороннего исследования возможностей использования НЧ $\mathrm{Ag}$ в сельском хозяйстве актуальна разработка надежных, эффективных и недорогих методов синтеза наночастиц $(18,19)$. Наиболее предпочтительно применение экологически безопасных и малотоксичных для организма человека восстановителей и стабилизаторов природного происхождения, таких как различные полимеры $(20,21)$, а также содержащийся в древесине лиственницы сибирской (Larix sibirica) и в портулаке огородном (Portulaca oleracea) полисахарид арабиногалактан $(22,23)$. Благодаря водорастворимости, термостабильности, биосовместимости, возможности использования в качестве восстановителя и стабилизатора при синтезе НЧ Ag, арабиногалактан рассматривается как перспективный биополимер для разработки наноструктур и нанокомпозитов сельскохозяйственного назначения $(24,25)$.

Перспективный способ безопасного и эффективного производства НЧ Ag - их восстановление из нитрата серебра методом так называемого «зеленого синтеза» с использованием мицелия грибов (26) и экстрактов растений $(27,28)$. Несмотря на привлекательность такого подхода, применение арабиногалактана для синтеза НЧ Ag представляется более предпочтительным, поскольку (в дополнение к биобезопасности метода) позволяет получать наночастицы в более контролируемых условиях биогенного синтеза и с более предсказуемыми свойствами.

В настоящей работе нами впервые установлено, что предпосевная 
обработка семян кресс-салата (Lepidium sativum L.) сорта Curled наночастицами серебра, стабилизированными биополимером арабиногалактаном и диоктилсульфосукцинатом, влияет на энергию прорастания, всхожесть и некоторые анатомо-морфометрические показатели проростков. Впервые показано, что НЧ Ag оказывают угнетающее действие на рост фитопатогенного гриба Fusarium sambucinum.

Целью работы была оценка потенциала использования наночастиц серебра, стабилизированных арабиногалактаном и диоктилсульфосукцинатом, в качестве средства стимуляции роста кресс-салата сорта Curled, a также изучение антифунгального действия полученных наночастиц на фитопатогенный токсинообразующий микромицет Fusarium sambucinum ВКПМ F-900.

Методика. Для синтеза наночастиц серебра использовали нитрат серебра (АО «ЛенРеактив», Россия), гидроксид аммония (27 \%), диоктилсульфосукцинат натрия - Aerosol-OT, или бис(2-этилгексил)сульфосукцинат, натриевая соль («Labtex», Россия), арабиногалактан («Fluka», Германия). Синтез проводили методом восстановления из нитрата серебра в щелочной среде в присутствии арабиногалактана. К 0,2 \% раствору арабиногалактана, нагретому до $90{ }^{\circ} \mathrm{C}$, при интенсивном перемешивании добавляли раствор нитрата серебра. Реакцию восстановления серебра проводили в течение 40 мин при той же температуре и $\mathrm{pH} \geq 10,0$ с последующим добавлением диоктилсульфосукцината натрия до конечной концентрации 0,8 \% и постепенным охлаждением раствора до комнатной температуры. Электрокинетический потенциал наночастиц серебра определяли на анализаторе Photocor compact Z (ООО «Фотокор», Россия). Просвечивающую электронную микроскопию проводили с помощью микроскопа LEO 912 AB («Carl Zeiss», Германия) при ускоряющем напряжении 100 кВ. Для приготовления образцов каплю золя наносили на медные сетки диаметром 3,05 мм, покрытые тонкой полимерной пленкой-подложкой, и высушивали при комнатной температуре. Распределение НЧ Ag по размерам определяли при обработке полученных микрофотографий, используя программу анализа оптических изображений ImageTool 3.00 («UTHSCSA», США).

Влияние НЧ Ag на энергию прорастания, всхожесть семян, рост гипокотиля и корня проростков кресс-салата сорта Curled оценивали в чашках Петри. Семена инкубировали в течение 1 ч в золях наночастиц с разными концентрациями серебра $(1,17 ; 2,34 ; 4,69 ; 9,38,18,75 ; 37,5 ; 75 ; 150$ мкг/мл). В каждом варианте эксперимента было три повторности по 100 семян в каждой. Контрольные семена инкубировали в воде. После завершения инкубации семена проращивали в чашках Петри на влажной фильтровальной бумаге в темноте при $20{ }^{\circ} \mathrm{C}$. На 3-и сут определяли энергию прорастания семян, на 5-е сут - всхожесть, на 7-е сут - длину гипокотиля и главного корня проростков.

Морфологию клеток L. sativum исследовали с помощью микроскопического анализа срезов корня 7-суточных проростков, обработанных золями со стимулирующей и ингибирующей концентрациями $\mathrm{Ag}$ (соответственно 4,69 и 18,75 мкг/мл). Контролем служили проростки, не обработанные золем наночастиц Ag. Предварительно готовили микропрепараты нефиксированных поперечных срезов толщиной 100-150 мкм. Срезы делали вручную в зоне проведения корней проростков, без предварительной или последующей фиксации. Выборка для каждой группы составляла 30 растений (по 10 из каждого из трех независимых экспериментов). Срезы помещали во включающую жидкость вода-глицерин (1:1) и изучали под световым микроскопом ЛОМО Микмед-6 (АО «ЛОМО», Россия) при увеличении 
$\times 100$ и $\times 400$. Фотосъемку осуществляли с использованием фотонасадки цифровой фотокамеры Canon Digital IXUS 80 IS («Canon», Япония). Снимки обрабатывали в программе Microsoft Office Picture Manager. Количественную обработку фотографий ( $n=10$ для каждой опытной группы) проводили в программе CellProfiler (https://cellprofiler.org) (29).

Антифунгальную активность золей наночастиц $\mathrm{Ag}$ оценивали методом диффузии в агар (30). В качестве тест-культуры использовали микромицет Fusarium sambucinum Fuckel BКПМ F-900, который культивировали на агаризованной среде Сабуро («ПанЭко», Россия). В лунки диаметром 10 мм вносили по 400 мкл золей $\mathrm{Ag}$ с концентрациями 9,38; 18,75; 37,5; 75; 150; 300 мкг/мл, приготовленных методом двойных последовательных разведений. Контроль - стерильная вода. Эксперимент проводили в трех повторностях, по 4 лунки на каждую дозу. Чашки Петри с тест-штаммом инкубировали в течение 5 сут при температуре $27{ }^{\circ} \mathrm{C}$, а затем просматривали на наличие вокруг лунок зон ингибирования.

Статистическую обработку результатов осушествляли в программе Microcal Origin 8.0 («OriginLab Corporation», США). Все данные в таблицах и рисунках представлены как средние арифметические значения $(M)$ и стандартные отклонения $( \pm \mathrm{SD})$. Для выявления статистической значимости различий применяли однофакторный дисперсионный анализ (ANOVA); различия считали достоверными при $\mathrm{p}<0,05$.

Результаты. Золь Ag был получен восстановлением нитрата серебра с помощью арабиногалактана, который одновременно выступал в роли как восстановителя, так и стабилизатора наночастиц. Для повышения устойчивости золя $\mathrm{Ag}$ к полученному препарату добавляли диоктилсульфосукцинат натрия. По данным просвечивающей электронной микроскопии, полученный препарат содержал НЧ Ag сферической формы (рис. 1, А). Средний

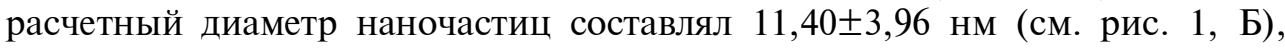
дзета-потенциал -24 мВ.
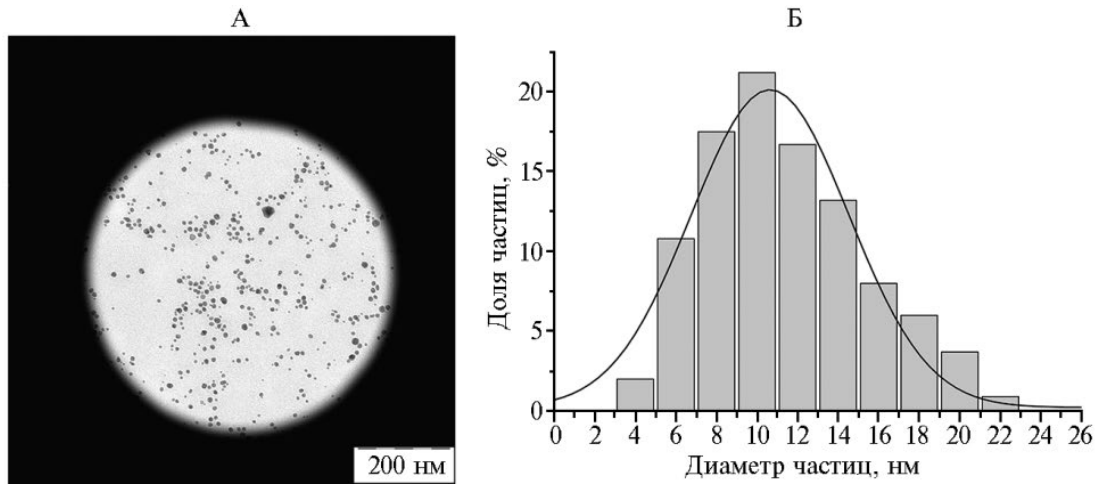

Рис. 1. Форма и размеры наночастиц серебра, стабилизированных арабиногалактаном и диоктилсульфосукцинатом, по данным просвечивающей электронной микроскопии: А - микрофотография образца золя серебра, полученная с помощью микроскопа LEO 912 AB («Carl Zeiss», Германия; увеличение $\times 1500)$, Б - гистограмма распределения наночастиц по размерам, полученная посредством обработки микрофотографий в программе UTHSCSA ImageTool 3.00.

Энергия прорастания семян кресс-салата в контрольной группе на 3-и сут эксперимента достигала $83,00 \pm 0,82$ \% (рис. 2, А). Между опытными группами по этому показателю наблюдались существенные различия. При наиболее низкой концентрации $\mathrm{Ag}$ в инкубационной среде (1,17 мкг/мл) не происходило стимуляции энергии прорастания (показатели статистически не различались). При концентрациях 2,34 и 4,69 мкг/мл наблюдался выраженный стимулирующий эффект наночастиц. При 4,69 мкг/мл он достигал 


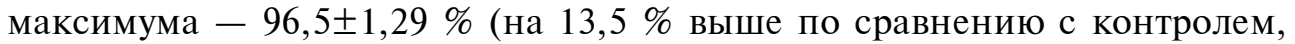
$\left.\mathrm{p}=2,1 \times 10^{-6}\right)$. В образцах семян, которые инкубировали в золях с высокими концентрациями Ag (9,38-150 мкг/мл), проявлялись дозозависимые ингибирующие эффекты. Максимальный ингибирующий эффект достигался при концентрации $\mathrm{Ag} 150$ мкг/мл (семена не проросли).
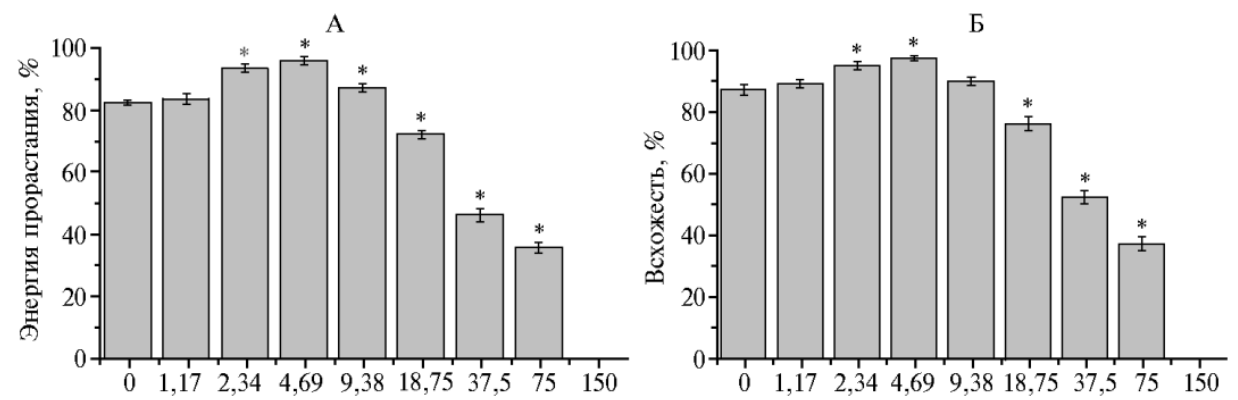

B

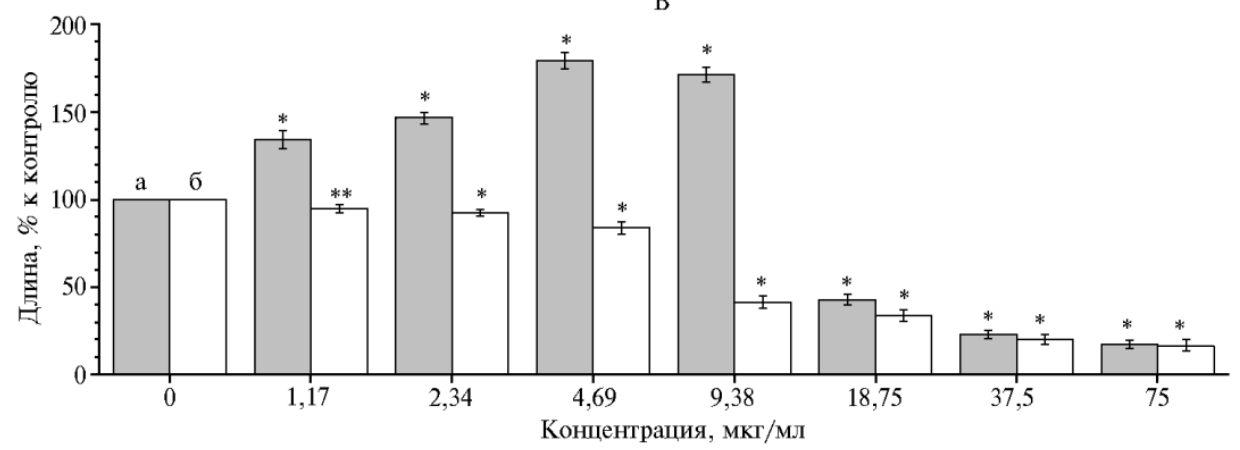

Рис. 2. Энергия прорастания (А), всхожесть семян (Б), длина главного корня (а, В) и гипокотиля (б, В) у проростков кресс-салата (Lepidium sativum L.) сорта Curled, обработанных золями наночастиц с различными концентрациями серебра $(n=10, M \pm \mathrm{SD})$.

*, ** Различия с контрольной группой статистически значимы соответственно при $\mathrm{p}<0,01$ и $\mathrm{p}<0,05$.

Всхожесть семян L. sativum определяли на 5-е сут проращивания. При инкубации семян в золе с концентрацией $\mathrm{Ag}$ 1,17 мкг/мл заметного влияния на всхожесть не наблюдалось $(\mathrm{p}=0,11)$ (см. рис. 2, Б). При 2,34 и 4,69 мкг/мл проявлялось стимулирующее действие наночастиц, и всхожесть возрастала по сравнению с контролем соответственно на 8,8 и 11,7 \% (соответственно $\mathrm{p}=3,5 \times 10^{-4}$ и $\left.\mathrm{p}=3,7 \times 10^{-5}\right)$. Всхожесть семян, которые инкубировали в золе с концентрацией $\mathrm{Ag} 9,38$ мкг/мл, была сопоставима с контролем $(\mathrm{p}=0,04)$. При более высоких концентрациях Ag в инкубационной среде этот показатель последовательно снижался и был существенно ниже, чем в контроле $(\mathrm{p}<0,01)$.

При концентрациях Ag 1,17; 2,34 и 4,69 мкг/мл в каждой из исследованных групп на 7-е сут происходило некоторое замедление развития гипокотиля при существенной дозозависимой стимуляции роста корня: длина корня у опытных образцов значительно превышала длину корня в контроле (соответственно на $34,4 \%, \mathrm{p}=8,9 \times 10^{-4} ; 46,4 \%, \mathrm{p}=8,2 \times 10^{-5}$ и $\left.79,1 \%, \mathrm{p}=6,3 \times 10^{-5}\right)$. После предварительной инкубации семян в золе $\mathrm{Ag} \mathrm{c}$

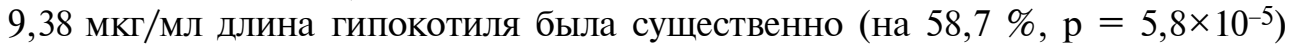
меньше, чем в контроле, а длина корня в опыте на 71,3\% превышала аналогичный показатель в контроле $\left(\mathrm{p}=5,8 \times 10^{-5}\right)$, что свидетельствует о значительном стимулирующем действии НЧ $\mathrm{Ag}$ на рост корня при подавлении роста гипокотиля. При инкубации семян в золях с более высокими 
концентрациями $\mathrm{Ag}(18,75 ; 37,5$ и 75 мкг/мл) наблюдалось последовательно нарастающее ингибирующее действие золей в отношении как гипокотиля, так и корня $(\mathrm{p}<0,01)$ (см. рис. 2, В).

A

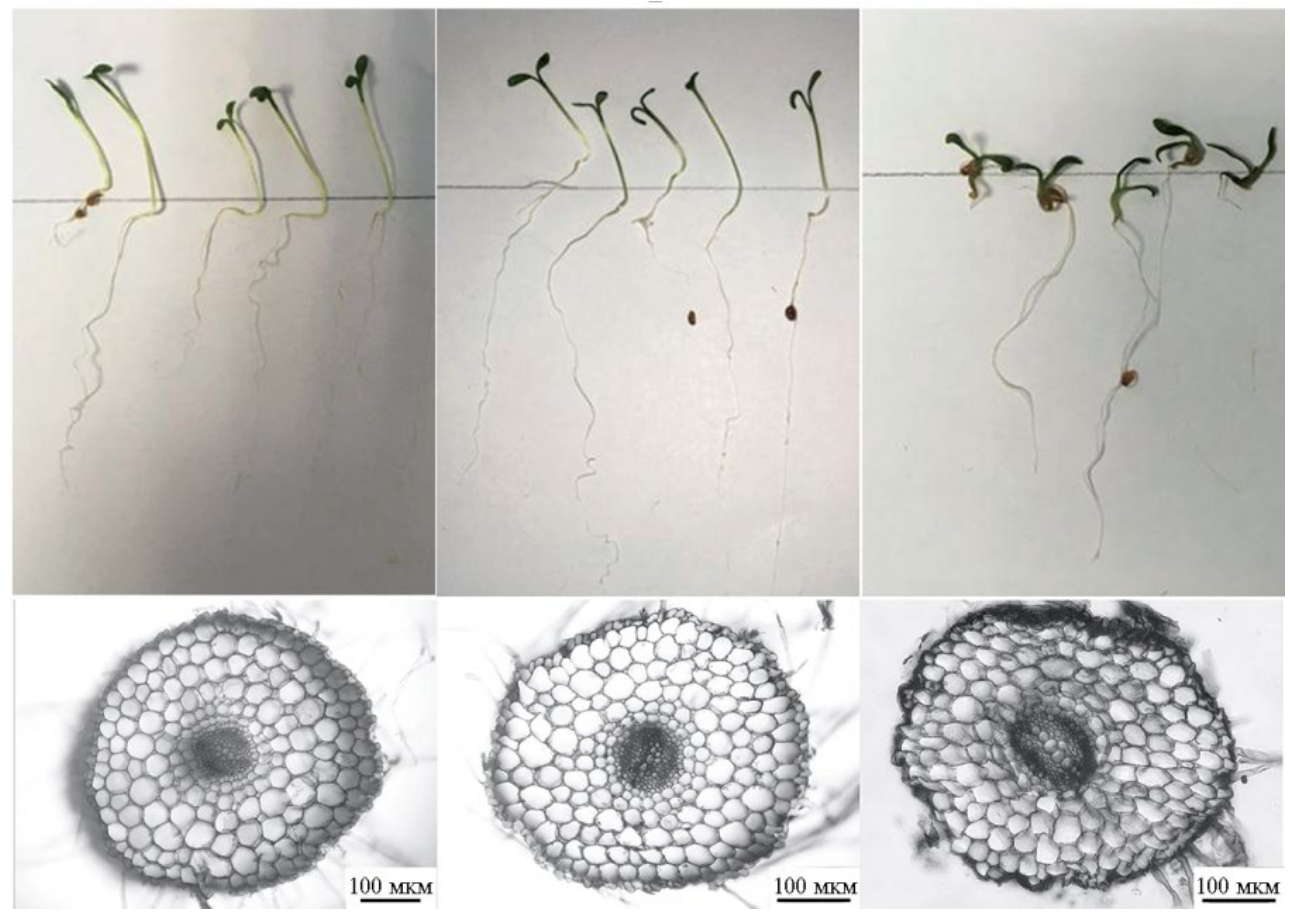

Рис. 3. Проростки кресс-салата (Lepidium sativum L.) сорта Curled после 7 сут проращивания семян, не обработанных (А) и обработанных золями наночастиц с концентрацией серебра 4,69 (Б) и 18,75 мкг/мл (В): вверху - общий вид; внизу - микрофотографии поперечных срезов корня (увеличение ×400, световой микроскоп ЛОМО Микмед-6, АО «ЛОМО», Россия).

При микроскопическом изучении срезов всасывающей зоны корня у проростков салата, не обработанных (контроль) и обработанных золями $\mathrm{Ag}$, у всех объектов наблюдалась характерная анатомическая картина первичного строения корней (рис. 3). В корне различались покровная ткань однослойная эпиблема, первичная кора, состоящая из 3-4 слоев мезодермы и одного внутреннего слоя эндодермы, а также центральный осевой цилиндр диархного строения. Клетки паренхимы мезодермы были кругловатоовальной формы с более или менее выраженными межклетниками прямоугольной формы.

Параметры анатомического строения корня проростков кресс-салата Lepidium sativum L. сорта Curled, обработанных золями наночастиц с различными концентрациями серебра $(n=3, M \pm \mathrm{SD})$

\begin{tabular}{l|c|c}
\hline Концентрация серебра, мкг/мл & Число сосудов, шт. & $\begin{array}{c}\text { Средний диаметр клеток } \\
\text { паренхимы, мкм }\end{array}$ \\
\hline Контроль (без обработки) & $12,5 \pm 3,8$ & $58,3 \pm 12,7$ \\
4,69 & $21,5 \pm 5,6^{*}$ & $34,2 \pm 5,9^{*}$ \\
18,75 & $13,9 \pm 4,1$ & $35,6 \pm 9,5^{*}$ \\
* Различия с контролем статистически значимы при $\mathrm{p}<0,05$. & \\
\hline
\end{tabular}

При сравнении анатомического строения контрольного и опытных образцов было установлено, что действие золя Ag в концентрации 4,69 мкг/мл (стимулирующая концентрация) проявлялось в формировании клеток па-

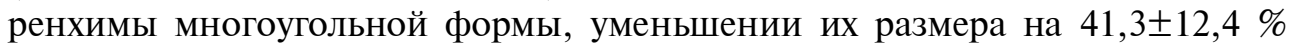


относительно контроля (табл.), а также тенденции к уменьшению площади межклетников паренхимы первичной коры, которые практически отсутствовали у образцов, обработанных золем в ингибирующей концентрации 18,75 мкг/мл. Золь в ингибирующей концентрации также оказывал влияние на клетки эпиблемы и периферические слои клеток мезодермы, выражающееся в утолщении клеточных стенок и уменьшении размера паренхимных клеток на 38,9 $18,8 \%$ по сравнению с контролем (p < 0,05) (см. табл.). НЧ $\mathrm{Ag}$ оказывали существенное влияние и на формирование проводящей системы центрального осевого цилиндра. Число сосудов ксилемы в корнях проростков, обработанных золем в стимулирующей концентрации серебра, было значительно болыше $(\mathrm{p}<0,05)$ в сравнении с таковым в контроле и при обработке золем в ингибирующей концентрации (см. табл. 1).

Размер наночастиц непосредственно связан не только с проявлением их физико-химических свойств, но и оказывает значительное влияние на биологическую активность (31). Чем меньше размеры НЧ, тем выше их удельная поверхность и активность в отношении преодоления физических и биологических барьеров. В настоящей работе были получены стабилизированные арабиногалактаном и диоктилсульфосукцинатом НЧ $\mathrm{Ag}$ весьма малого размера $(11,40 \pm 3,96$ нм), что может быть одной из важных причин их активного проникновения через семенную кожуру и стимуляции энергии прорастания, всхожести семян, а также роста кресс-салата. Очевидно, что такая стимуляция возможна при умеренно низких концентрациях НЧ (2,34 и 4,69 мкг/мл), поскольку более высокие могут подавлять рост растения в результате повреждающего действия в отношении биомембран, макромолекул, а также нарушения целостности клеточных органелл, что согласуется с данными работы R. Kaveh с соавт. (32). Действие золя с высокой концентрацией НЧ Ag (18,75 мкг/мл), напротив, приводит к ингибированию образования проводящих элементов корня, подавлению роста корневой системы и замедлению развития растения.

Положительное действие наночастиц в отношении роста растений может быть связано со стимуляцией фотосинтетических процессов, а также с активацией системы синтеза ауксинов в меристематических тканях (18). Изучение морфологии корня в нашей работе показало, что действие НЧ Ag в концентрации 4,69 мкг/мл приводило к формированию многочисленных проводящих элементов, что было одной из важных причин активации роста корневой системы и всего растения благодаря улучшению снабжения водой и минеральными веществами. Продемонстрированный нами эффект дозозависимой стимуляции роста корня кресс-салата согласуется с данными работы J. Geisler-Lee c соавт. (33), в которой авторы проводили эксперименты с Arabidopsis thaliana и отмечали накопление наночастиц серебра в корневом чехлике проростков. Очевидно, что специфика распределения наночастиц в тканях растения оказывает влияние на преимущественный рост тех или иных тканей, однако механизм такого действия пока не установлен.

В настоящей работе мы также установили способность стабилизированных наночастиц металлического серебра к подавлению роста фитопатогенного гриба F. sambucinum. Грибы рода Fusarium - плесневые фитопатогены, продуцирующие опасные для здоровья человека микотоксины (11). Поскольку источниками микотоксинов могут быть пораженные грибами зеленые растения, корма для животных, а также пищевые продукты, важной задачей представляется поиск новых и расширение арсенала уже имеющихся эффективных средств борьбы с плесневыми грибами.

Золи оказывали дозозависимое подавляющее действие на рост 
F. sambucinum ВКПМ F-900. При концентрации 9,38 мкг/мл угнетения роста гриба мы не наблюдали. Минимальная ингибирующая концентрация, которая угнетала видимый рост тест-штамма $F$. sambucinum, составляла 18,75 мкг/мл (зона угнетения роста $11,7 \pm 0,8$ мм). При концентрациях НЧ $\mathrm{Ag} 37,5 ; 75 ; 150 ; 300$ мкг/мл диаметр зоны угнетения роста составлял соответственно $12,9 \pm 0,9 ; 21,1 \pm 2,7 ; 28,4 \pm 3,9 ; 32,4 \pm 4,2$ мм. Антифунгальное действие может быть обусловлено повреждением наночастицами Аg клеточной стенки и фосфолипидных мембран, а также нарушением нормального функционирования элементов дыхательной цепи и ядерной ДНК гриба, вызванным ионами серебра, диссоциирующими от наночастиц в биологических средах (34). Угнетение роста $F$. sambucinum позволяет рассматривать препарат в качестве потенциального средства повышения урожайности и защиты растений и сельскохозяйственной продукции от плесневых грибов и опасных для здоровья человека микотоксинов.

Таким образом, инкубация семян Lepidium sativum L. сорта Curled в золях наночастиц (НЧ) с концентрацией серебра 2,34 и 4,69 мкг/мл оказывала стимулирующее действие на энергию прорастания и всхожесть семян кресс-салата, а также значительно стимулировала рост корня проростков при некотором замедлении роста гипокотиля. НЧ Ag в концентрации 4,69 мкг/мл оказывали стимулирующий эффект на развитие проводящей системы корня. При применении для обработки семян золей с концентрацией $\mathrm{Ag}$, превышающей 4,69 мкг/мл, проявлялись их токсические эффекты, вызывавшие подавление роста растений. Инкубация семян в золях НЧ Ag c концентрацией от 18,75 мкг/мл и выше приводила к существенному снижению энергии прорастания и всхожести, а также к подавлению роста растений. Золи серебра также оказывали угнетающее действие на рост фитопатогенного микромицета Fusarium sambucinum (минимальная ингибирующая концентрация составляла 18,75 мкг/мл). Следовательно, стабилизированные арабиногалактаном и диоктилсульфосукцинатом золи серебра имеют значительный потенциал для стимуляции роста и защиты культурных растений от фитопатогенов. Для более полного и детального определения возможностей применения стабилизированных золей серебра в сельском хозяйстве требуются дополнительные исследования.

\section{ЛИТЕРАТУРА}

1. Bhagat Y., Gangadhara K., Rabinal C., Chaudhari G., Ugale P. Nanotechnology in agriculture: a review. Journal of Pure and Applied Microbiology, 2015, 9(1): 737-747.

2. Jampílek J., Králová K. Application of nanotechnology in agriculture and food industry, its prospects and risks. Ecological Chemistry and Engineering S, 2015, 22(3): 321-361 (doi: 10.1515/eces2015-0018).

3. Hossain Z., Mustafa G., Komatsu S. Plant responses to nanoparticle stress. International Journal of Molecular Sciences, 2015, 16(11): 26644-26653 (doi: 10.3390/ijms161125980).

4. Gusev A.A., Kudrinsky A.A., Zakharova O.V., Klimov A.I., Zherebin P.M., Lisichkin G.V., Vasyukova I.A., Denisov A.N., Krutyakov Y.A. Versatile synthesis of PHMB-stabilized silver nanoparticles and their significant stimulating effect on fodder beet (Beta vulgaris L.). Materials Science and Engineering C, 2016, 62: 152-159 (doi: 10.1016/j.msec.2016.01.040).

5. Zhang B., Zheng L.P., Li W.Y., Wang J.W. Stimulation of artemisinin production in Artemisia annua hairy roots by $\mathrm{Ag}-\mathrm{SiO} 2$ core-shell nanoparticles. Current Nanoscience, 2013, 9(3): 363-370 (doi: 10.2174/1573413711309030012).

6. Salama H.M.H. Effects of silver nanoparticles in some crop plants, Common bean (Phaseolus vulgaris L.) and corn (Zea mays L.). International Research Journal of Biotechnology, 2012, 3(10): 190-197.

7. Seifsahandi M., Sorooshzadeh A., Rezazadeh H., Naghdiabadi H.A. Effect of nano silver and silver nitrate on seed yield of borage. Journal of Medicinal Plants Research, 2011, 5(2): 171-175.

8. Yin L.Y., Cheng Y.W., Espinasse B., Colman B.P., Auffan M., Wiesner M., Rose J., Liu J., Bernhardt E.S. More than the ions: the effects of silver nanoparticles on Lolium multiflorum. 
Environmental Science and Technology, 2011, 45(6): 2360-2367 (doi: 10.1021/es103995x).

9. Jiang H.S., Li M., Chang F.Y., Li W., Yin L.Y. Physiological analysis of silver nanoparticles and $\mathrm{AgNO}_{3}$ toxicity to Spirodela polyrhiza. Environmental Toxicology and Chemistry, 2012, 31(8): 1880-1886 (doi: 10.1002/etc.1899).

10. Mirzajani F., Askari H., Hamzelou S., Farzaneh M., Ghassempour A. Effect of silver nanoparticles on Oryza sativa L. and its rhizosphere bacteria. Ecotoxicology and Environmental Safety, 2013, 88: 48-54 (doi: 10.1016/j.ecoenv.2012.10.018).

11. Richard J.L. Some major mycotoxins and their mycotoxicoses - an overview. International Journal of Food Microbiology, 2017, 119(1-2): 3-10 (doi: 10.1016/j.ijfoodmicro.2007.07.019).

12. Khadri H., Alzohairy M., Janardhan A., Kumar A.P., Narasimha G. Green synthesis of silver nanoparticles with high fungicidal activity from olive seed extract. Advances in Nanoparticles, 2013, 2(3): 241-246 (doi: 10.4236/anp.2013.23034).

13. Gajbhiye M., Kesharwani J., Ingle A., Gade A., Rai M. Fungus-mediated synthesis of silver nanoparticles and their activity against pathogenic fungi in combination with fluconazole. Nanomedicine: Nanotechnology, Biology, and Medicine, 2009, 5(4): 382-386 (doi: 10.1016/j.nano.2009.06.005).

14. Elgorban A.M., El-Samawaty A.E.-R.M., Yassin M.A., Sayed S.R., Adil S.F., Elhindi K.M., Bakri M., Khan M. Antifungal silver nanoparticles: Synthesis, characterization and biological evaluation. Biotechnology and Biotechnological Equipment, 2016, 30(1): 56-62 (doi: 10.1080/13102818.2015.1106339).

15. Mishra S., Singh B.R., Singh A., Keswani C., Naqvi A.H., Singh H.B. Biofabricated silver nanoparticles act as a strong fungicide against Bipolaris sorokiniana causing spot blotch disease in wheat. PLoS ONE, 2014, 9(5): e97881 (doi: 10.1371/journal.pone.0097881).

16. Jo Y.-K., Kim B.H., Jung G. Antifungal activity of silver ions and nanoparticles on phytopathogenic fungi. Plant Disease, 2009, 93(10): 1037-1043 (doi: 10.1094/PDIS-93-10-1037).

17. Kim S.W., Jung J.H., Lamsal K., Kim Y.S., Min J.S., Lee Y.S. Antifungal effects of silver nanoparticles (AgNPs) against various plant pathogenic fungi. Mycobiology, 2012, 40(1): 53-58 (doi: 10.5941/MYCO.2012.40.1.053).

18. Almutairi Z.M., Alharbi A.A. Effect of silver nanoparticles on seed germination of crop plants. Journal of Advances in Agriculture, 2015, 4(1): 280-285 (doi: 10.24297/jaa.v4i1.4295).

19. Nair R., Varghese S.H., Nair B.G., Maekawa T., Yoshida Y., Kumar D.S. Nanoparticulate material delivery to plants. Plant Science, 2010, 179(3): 154-163 (doi: 10.1016/j.plantsci.2010.04.012).

20. Maity D., Kanti Bain M., Bhowmick B., Sarkar J., Saha S., Acharya K., Chakraborty M., Chattopadhyay D. In situ synthesis, characterization, and antimicrobial activity of silver nanoparticles using water soluble polymer. Journal of Applied Polymer Science, 2011, 122(4): 2189-2196 (doi: 10.1002/app.34266).

21. Lukman A.I., Gong B., Marjo C.E., Roessner U., Harris A.T. Facile synthesis, stabilization, and anti-bacterial performance of discrete Ag nanoparticles using Medicago sativa seed exudates. Journal of Colloid and Interface Science, 2011, 353(2): 433-444 (doi: 10.1016/j.jcis.2010.09.088).

22. Grishchenko L.A., Medvedeva S.A., Aleksandrova G.P., Feoktistova L.P., Sapozhnikov A.N., Sukhov B.G., Trofimov B.A. Redox reactions of arabinogalactan with silver ions and formation of nanocomposites. Russian Journal of General Chemistry, 2006, 76(7): 1111-1116 (doi: 10.1134/S1070363206070189).

23. Anuradha K., Bangal P., Madhavendra S.S. Macromolecular arabinogalactan polysaccharide mediated synthesis of silver nanoparticles, characterization and evaluation. Macromolecular Research, 2016, 24(2): 152-162 (doi: 10.1007/s13233-016-4018-4).

24. Alexandrova V.A., Shirokova L.N., Sadykova V.S., Baranchikov A.E. Antimicrobial activity of silver nanoparticles in a carboxymethyl chitin matrix obtained by the microwave hydrothermal method. Applied Biochemistry and Microbiology, 2018, 54(5): 496-500 (doi: 10.1134/S0003683818050046).

25. Sukhov B.G., Aleksandrova G.P., Grishchenko L.A., Feoktistova L.P., Sapozhnikov A.N., Proidakova O.A., T'Kov A.V., Medvedeva S.A., Trofimov B.A. Nanobiocomposites of noble metals based on arabinogalactan: preparation and properties. Journal of Structural Chemistry, 2007, 48(5): 922-927 (doi: 10.1007/s10947-007-0136-3).

26. Ahmad A., Mukherjee P., Senapati S., Mandal D., Khan M.I., Kumar R., Sastry M. Extracellular biosynthesis of silver nanoparticles using the fungus Fusarium oxysporum. Colloids and Surfaces B: Biointerfaces, 2003, 28(4): 313-318 (doi: 10.1016/S0927-7765(02)00174-1).

27. Gurunathan S. Biologically synthesized silver nanoparticles enhance antibiotic activity against Gram-negative bacteria. Journal of Industrial and Engineering Chemistry, 2015, 29: 217-226 (doi: 10.1016/j.jiec.2015.04.005).

28. Gurunathan S., Jeong J.K., Han J.W., Zhang X.F., Park J.H., Kim J.H. Multidimensional effects of biologically synthesized silver nanoparticles in Helicobacter pylori, Helicobacter felis, and human lung (L132) and lung carcinoma A549 cells. Nanoscale Research Letters, 2015, 10(1): 1-17 (doi: 10.1186/s11671-015-0747-0).

29. Lamprecht M.R., Sabatini D.M., Carpenter A.E. CellProfiler ${ }^{\mathrm{TM}}$ : free, versatile software for automated biological image analysis. Biotechniques, 2007, 42(1): 71-75 (doi: 10.2144/000112257). 
30. Balouiri M., Sadiki M., Ibnsouda S.K. Methods for in vitro evaluating antimicrobial activity: a review. Journal of Pharmaceutical Analysis, 2016, 6(2): 71-79 (doi: 10.1016/j.jpha.2015.11.005).

31. Shah M., Fawcett D., Sharma S., Tripathy S.K., Poinern G.E.J. Green synthesis of metallic nanoparticles via biological entities. Materials, 2015, 8(11): 7278-7308 (doi: 10.3390/ma8115377).

32. Kaveh R., Li Y.-S., Ranjbar S., Tehrani R., Brueck C.L., Van Aken B. Changes in Arabidopsis thaliana gene expression in response to silver nanoparticles and silver ions. Environmental Science and Technology, 2013, 47(18): 10637-10644 (doi: 10.1021/es402209w).

33. Geisler-Lee J., Wang Q., Yao Y., Zhang W., Geisler M., Li K., Huang Y., Chen Y., Kolmakov A., Ma X. Phytotoxicity, accumulation and transport of silver nanoparticles by Arabidopsis thaliana. Nanotoxicology, 2013, 7(3): 323-337 (doi: 10.3109/17435390.2012.658094).

34. Velmurugan N., Kumar G., Han S.S., Nahm K.S., Lee Y.S. Synthesis and characterization of potential fungicidal silver nano-sized particles and chitosan membrane containing silver particles. Iranian Polymer Journal (English Edition), 2009, 18(5): 383-392.

\author{
${ }_{1}$ ФГАОУ ВО Первый московский государственный \\ медицинский университет им. И.М. Сеченова \\ Министерства здравоохранения Российской Федерации \\ (Сеченовский Университет), \\ 119991 Россия, г. Москва, ул. Трубецкая, д. 8, стр. 2, \\ e-mail: senia501@yandex.ru, bobkovamma@mail.ru,n feldman@mail.ru $\bowtie$, \\ luferovc@mail.ru,gromovykhtatyana@mail.ru, laznata@mail.ru, \\ svlutsenko57@mail.ru; \\ $23 А О$ «Концерн «Наноиндустрия», \\ 119334 Россия, г. Москва, ул. Бардина, д. 4, к. 1, \\ e-mail: nanotech@nanotech.ru
}

Sel'skokhozyaistvennaya biologiya [Agricultural Biology], 2021, V. 56, № 3, pp. 500-510

\title{
STUDY OF THE BIOLOGICAL ACTIVITY OF ARABINOGALACTAN-STABILIZED SILVER NANOPARTICLES TOWARDS WATERCRESS Lepidium sativum L. Curled AND PLANT PATHOGENIC MICROMYCETE Fusarium sambucinum
}

\author{
O.I. Gudkoval, N.V. Bobkova ${ }^{1}$, N.B. Feldman ${ }^{1}{ }^{凶}$, A.N. Luferov' ${ }^{1}$, T.I. Gromovykh ${ }^{1}$, \\ I.A. Samylina ${ }^{1}$, M.A. Ananyan ${ }^{2}$, S.V. Lutsenko ${ }^{1}$
}

${ }^{1}$ Sechenov First Moscow State Medical University (Sechenov University), the Ministry of Health of the Russian Federation, 8-2, ul. Trubetskaya, Moscow, 119991 Russia, e-mail senia501@yandex.ru, bobkovamma@mail.ru,n_feldman@mail.ru (corresponding author $\bowtie$ ), luferovc@mail.ru, gromovykhtatyana@mail.ru, laznata@mail.ru, svlutsenko57@mail.ru;

${ }^{2}$ Nanoindustry Concern JSC, 4-1, ul. Bardina, Moscow, 119334 Russia, e-mail nanotech@nanotech.ru ORCID:

Gudkova O.I. orcid.org/0000-0003-3880-5587

Bobkova N.V. orcid.org/0000-0003-1591-4019

Feldman N.B. orcid.org/0000-0001-6098-2788

Luferov A.N. orcid.org/0000-0003-2397-7378

The authors declare no conflict of interests

Acknowledgements:

Supported financially by the Russian academic excellence project (Project "5 in 100")

Received January 15, 2021

Gromovykh T.I. orcid.org/0000-0002-6943-534X

Samylina I.A. orcid.org/0000-0002-4895-0203

Ananyan M.A. orcid.org/0000-0002-1588-1475

Lutsenko S.V. orcid.org/0000-0002-2017-6025

Abstract

Metal nanoparticles (NPs) exhibiting growth-stimulating, antifungal, antibacterial, insecticidal effects and prolonged release of minerals and herbicides, opens up prospects for increasing the yield of crops. Among metal nanoparticles that can find application in agriculture, silver nanoparticles occupy a special place due to a wide spectrum of biological activity. In this work, we have established for the first time that the pre-sowing treatment of seeds of watercress Lepidium sativum L. cv. Curled by silver nanoparticles which are stabilized by the biopolymer arabinogalactan and dioctyl sulfosuccinate affects the germinative energy, laboratory seed germination and some anatomical and morphometric parameters of watercress seedlings. It was shown for the first time that silver nanoparticles have an inhibitory effect on the growth of the phytopathogenic fungus Fusarium sambucinum. This work aimed to assess both the stimulating effect of silver nanoparticles (Ag-NPs) stabilized with arabinogalactan and dioctyl sulfosuccinate on growth of watercress Lepidium sativum L. cv. Curled seedlings and the antifungal effect on a plant pathogenic toxin-producing micromycete Fusarium sambucinum VKPM F900. The nanoparticles were synthesized by the reduction of silver nitrate in an alkaline medium in the presence of arabinogalactan followed by the addition of dioctyl sulfosuccinate as a stabilizer. The average nanoparticle diameter was $11.40 \pm 3.96 \mathrm{~nm}$; zeta potential $-24 \mathrm{mV}$. The effect of silver 
nanoparticles on germination energy, seed germination, growth of watercress seedling hypocotyl and root was investigated. Seeds were incubated in sols of nanoparticles with various silver concentrations $(1.17,2.34,4.69,9.38,18.75 .37 .5,75$, and $150 \mu \mathrm{g} / \mathrm{ml})$. Control seeds were incubated in water. After incubation, the seeds were germinated in Petri dishes on a wet bed of filter paper in the dark at $20{ }^{\circ} \mathrm{C}$. The seed germination energy was determined on day 3, the laboratory germination - on day 5 , the lengths of the hypocotyl and the main root were measured on day 7 , and also microscopic analysis of the root sections of seedling treated with sols with stimulating and inhibiting concentrations of $\mathrm{Ag}$ (4.69 and $18.75 \mu \mathrm{g} / \mathrm{ml}$, respectively) was carried out. Antifungal activity of silver sols with concentrations from 9.38 to $300 \mu \mathrm{g} / \mathrm{ml}$ was assessed by the agar diffusion method. Micromycete Fusarium sambucinum Fuckel VKPM F-900 was used as a test culture to determine antifungal activity. Sterile water was used as a control. The incubation of seeds in sols with a silver concentration of 2.34 and 4.69 $\mu \mathrm{g} / \mathrm{ml}$ had a stimulating effect on the germination energy and laboratory germination of L. sativum seeds. A dose of silver nanoparticles of $4.69 \mu \mathrm{g} / \mathrm{ml}$ increased the germination energy by $13.5 \%$ and laboratory germination by $11.7 \%$ compared to the control. In addition, the concentrations of silver from 1.17 to $4.69 \mu \mathrm{g} / \mathrm{ml}$ had a significant stimulating effect on root growth (from 34.4 to $79.1 \%$, respectively) with some deceleration of hypocotyl growth. Seed incubation in sols with a silver concentration of $18.75 \mu \mathrm{g} / \mathrm{ml}$ and higher led to a significant decrease in the germination energy and laboratory germination, as well as suppression of plant growth. Microscopic examination of sections of zone of maturation of the root of seedlings showed that silver sols significantly affect the conductive system of the central axial cylinder. The number of xylem vessels in seedlings treated with silver sol at a stimulating concentration of $4.69 \mu \mathrm{g} / \mathrm{ml}$ was significantly higher compared to the control, which led to a more intensive growth of the root system and the whole plant. Silver nanoparticles also inhibit the growth of $F$. sambucinum. The growth inhibition zone at a maximum sol concentration of $300 \mu \mathrm{g} / \mathrm{ml}$ was $32.4 \pm 4.2 \mathrm{~mm}$ in diameter, and at $150 \mu \mathrm{g} / \mathrm{ml}$ it was $28.4 \pm 3.9 \mathrm{~mm}$. The minimum concentration inhibiting the visible growth of the test strain $F$. sambucinum was $18.75 \mu \mathrm{g} / \mathrm{ml}$ (growth inhibition zone $11.7 \pm 0.8 \mathrm{~mm}$ ). The presented data indicate the possibility of using sols of stabilized silver nanoparticles to stimulate seed germination and plant growth and to protect plants against pathogens.

Keywords: silver nanoparticles, plant growth, germinative energy, seed germination, antifungal activity, Lepidium sativum, Fusarium sambucinum. 